\title{
Stepwise conformational cooling towards a single isomeric state in the four internal rotors system 1,2-butanediol
}

\author{
Igor D. Reva,* António J. Lopes Jesus, Mário T. S. Rosado, Rui Fausto, \\ M. Ermelinda Eusébio and J. S. Redinha
}

Received 31st July 2006, Accepted 27th September 2006

First published as an Advance Article on the web 20th October 2006

DOI: $10.1039 / b 610962 d$

The present work explores the possibilities of the matrix isolation technique in the structural characterisation of highly flexible molecules. To date, most studies of this type were carried out on molecules with three or less internal degrees of freedom and a few (less than 10) possible conformations. The molecule of 1,2-butanediol has four conformationally relevant three-fold rotational axes, which can result in 81 possible conformations. A detailed theoretical study, at the MP2 and DFT(B3LYP) levels of theory with the $6-311++\mathrm{G}(\mathrm{d}, \mathrm{p})$ basis set, revealed that more than 20 conformers of 1,2-butanediol have relative energies in a $0-10 \mathrm{~kJ} \mathrm{~mol}^{-1}$ range and contribute appreciably to the gas phase equilibrium at room temperature. This fact renders conformational studies of the system extremely difficult under normal conditions. However, the method of matrix isolation permits the reduction of the number of populated conformational states in the experiment at low temperature due to the effect known as conformational cooling: low energy barriers promote the relaxation of the higher energy local minima into more stable structures. As a result of massive conformational cooling occurring upon matrix deposition, only five conformers of 1,2-butanediol were retained in the samples at $10 \mathrm{~K}$. These conformers were identified using a combination of FTIR spectroscopy and extensive theoretical calculations of vibrational spectra. Annealing of the matrices up to $50 \mathrm{~K}$ resulted in the extreme case of conformational cooling related with the depopulation of all conformers into the most stable unique structure. The observed transformations were rationalized in terms of barriers to intramolecular rotation.

\section{Introduction}

Butanediols represent an interesting class of molecules with several possibilities of intramolecular interactions between the polar groups. Moreover, the molecular backbone containing four carbon and two oxygen atoms possesses a high flexibility resulting from the existence of several relevant torsional angles. Depending on the position of the hydroxyl groups, a different number of intramolecular degrees of freedom exist in the isomers of the vicinal butanediols. The previously studied 2,3-butanediol ${ }^{1}$ has only three conformationally relevant dihedral angles, and the total number of unique structures is further reduced, due to the symmetry relations, to less than 20 conformers. In the case of 1,2-butanediol (1,2-BD), there are five intramolecular rotational degrees of freedom $\left[\mathrm{HO}-\mathrm{CH}_{2}-\mathrm{CH}(-\mathrm{OH})-\mathrm{CH}_{2}-\mathrm{CH}_{3}\right]$ and four of them (all except the rotation of the terminal methyl group) are conformationally relevant. Existence of a three-fold axis around each of the four dihedral angles can result in a total of $3^{4}=81$ conformations, that complicates the structural studies of 1,2-butanediol.

As will be shown later in this study, more than twenty conformers of 1,2-butanediol (1,2-BD) have relative energies

Departamento de Química, Universidade de Coimbra, 3004-535

Coimbra, Portugal.E-mail: reva@qui.uc.pt; Fax: + 351 239-827-703; Tel: + 351 239-854-483 in the $0-10 \mathrm{~kJ} \mathrm{~mol}^{-1}$ range, and are expected to contribute significantly to the conformational equilibrium at room temperature. Clearly, with such a large number of structures, it is very difficult to carry out conformational studies of individual forms of 1,2-BD with experimental techniques like microwave spectroscopy or gas phase electron diffraction.

Previous experimental studies of 1,2-butanediol addressed mainly the thermodynamic properties of this compound in the bulk. ${ }^{2}$ Infrared spectroscopic studies on its structure and on other vicinal butanediols are very scarce. Studies in dilute solution of inert solvents, ${ }^{3,4}$ vapour phase ${ }^{3,5}$ and matrix isolation $^{5}$ only report average characteristics. For example, they have shown the presence of a lower frequency band in the $\mathrm{OH}$ stretching region in addition to the absorption band due to the free $\mathrm{OH}$ (higher frequency band). This lower frequency absorption was assigned to the presence of an intramolecular hydrogen bond between the two hydroxyl groups. ${ }^{1} \mathrm{H}$ NMR and ${ }^{13} \mathrm{C}$ NMR studies ${ }^{6}$ performed on 2,3-butanediol confirm the existence of this interaction in solvents of low polarity whereas in more polar solvents there is no evidence of intramolecular H-bond.

Computational studies performed on 1,2-BD are also very scarce. A molecular mechanics investigation published twenty years ago ${ }^{7}$ showed that, as in other simple vicinal diols, ${ }^{8}$ the gauche OCCO conformations in 1,2-BD appear to be more stable than those where the OCCO skeleton assumes a trans 
conformation, due to the formation of an intramolecular hydrogen bond in the former conformations. More recently, a study of the molecular structure of butanediol isomers, combining DFT calculations with IR spectroscopy in carbon tetrachloride solutions at room temperature, was performed in our laboratory. ${ }^{9}$ In that work it was concluded that the energy differences between the isomers in gas state are higher than those in liquid state. Moreover, it has been shown that the intramolecular hydrogen bonding plays a determinant role in the conformational behavior of the isolated molecules.

The aim of the present work is to study the conformational behavior of monomeric 1,2-butanediol isolated in solidified matrices of inert gases. The matrix isolation technique turns possible experimental investigation of the higher energy conformers at low temperatures. Usually, the freezing of the sample (typically at $10 \mathrm{~K}$ ) is sufficiently fast so the system remains in a state of non-equilibrium, wherein the conformational composition of the sample is characteristic of the hot vapour (typically at room temperature) prior to deposition. ${ }^{10}$ This non-equilibrium condition is met when the barriers for intramolecular rearrangements are high enough.

Upon heating of the matrix (annealing), the thermal energy provided can be sufficient to surpass some barriers, allowing the system to progress, in terms of conformational distribution, towards the thermal equilibrium at the actual matrix temperature. This is the conformational cooling process. The reverse path can be disregarded, as it would shift the system away from the thermal equilibrium.

By choosing proper temperature conditions, the number of species that are retained in the samples can be controlled and substantially reduced in comparison to room temperature equilibrium. The experimental infrared spectra become simplified and information about the presence or absence in the sample of particular forms can be extracted from the experiment.

\section{Results and discussion}

\section{Conformations of 1,2-butanediol}

The 1,2-butanediol molecule has four conformationally relevant dihedral angles, two of them related to the heavy atom backbone (OCCO and CCCC) and the other two related to the arrangement of the hydroxyl groups (HOCC) (see Scheme 1 where the atom numbering adopted in this work is also provided). Considering three conformational possibilities (trans: $180^{\circ}$, +gauche: $60^{\circ}$ and -gauche: $-60^{\circ}$ ) for each relevant dihedral angle, unique names can be given to all possible conformers. In this study, the conformers of 1,2-BD are identified by combinations of four letters. The letters are related with the values of the dihedral angles: $g$ or $G$ stands for

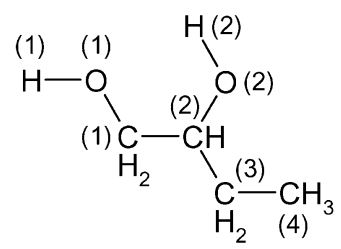

Scheme 1 Atom numbering for the molecule of 1,2-butanediol used in the manuscript.
+ gauche $\left(\mathrm{ca} .+60^{\circ}\right) ; \mathrm{g}^{\prime}$ or $\mathrm{G}^{\prime}$ stands for -gauche $\left(\mathrm{ca} .-60^{\circ}\right) ; \mathrm{t}$ or T stands for trans $\left(\mathrm{ca} .180^{\circ}\right)$. The capital letters (T, G, G') refer to the heavy atom backbone structure while the lowercase $\left(\mathrm{t}, \mathrm{g}, \mathrm{g}^{\prime}\right)$ describe the positions of the $\mathrm{OH}$ groups. The second and third letters define the OCCO and CCCC dihedral angles, respectively, while the first and fourth letters define the $\mathrm{H}(1) \mathrm{O}(1) \mathrm{C}(1) \mathrm{C}(2)$ and $\mathrm{C}(1) \mathrm{C}(2) \mathrm{O}(2) \mathrm{H}(2)$ dihedral angles. Also, in the discussion of the conformational structures letters $\mathrm{X}$ and $\mathrm{x}$ are used as wildcards designating the complete sets $\left(\mathrm{G}^{\prime}, \mathrm{G}, \mathrm{T}\right)$ and $\left(\mathrm{g}^{\prime}, \mathrm{g}, \mathrm{t}\right)$, respectively.

The highest possible symmetry of the 1,2-BD molecule is $\mathrm{C}_{1}$, which means that all possible minima are formally different. There is one chiral centre in the molecule, which can result in two enantiomers $(R$ and $S$ ). At the monomer level, they are spectroscopically, conformationally and energetically equal. To simplify the discussion, only one form (with the $R$ configuration around the chiral centre) will be considered in this study.

The random conformational search method ${ }^{11}$ showed that, of the 81 possible local minima on the potential energy surface of 1,2-BD, about one third part of the structures fall into the energy range $0-15 \mathrm{~kJ} \mathrm{~mol}^{-1}$ with respect to the most stable conformer. These forms were submitted to full geometry optimization and calculations of the infrared spectra at higher levels of theory. For the structures in the $0-10 \mathrm{~kJ} \mathrm{~mol}^{-1}$ range, the calculated relative energies at $0 \mathrm{~K}$ (represented as the sum of the electronic and zero point vibrational energies, $E_{\mathrm{e}}+$ ZPE) and at room temperature (298 K, represented as the sum of the electronic and thermal Gibbs free energies) are displayed in Table 1. The conformational populations at $298 \mathrm{~K}$ (nozzle temperature) were calculated using the Boltzmann distribution based on the Gibbs energy values, and are also shown in Table 1. Conformers sharing the same heavy atom backbone configuration, defined by the OCCO and CCCC dihedral angles, are grouped in the table into families. The families are identified by two letters (middle column of Table 1 , shown in bold typeface), corresponding to the second and third letters of the names of the individual conformers (first column).

In addition to the unique four-letter names, a consecutive number was attributed to each conformer, according to its relative energy at $0 \mathrm{~K}$ as calculated at the MP2/6$311++\mathrm{G}(\mathrm{d}, \mathrm{p})$ level. The relative energies are shown in Table 1 with exaggerated accuracy (two decimal digits) in order to demonstrate very small differences. One can see that the relative stability of conformers in energy changes with the change of model chemistry (DFT vs. MP2) and also after accounting for the thermal corrections to $298 \mathrm{~K}$. However, the absolute variations are very small.

It is interesting to note that more than $96 \%$ of the equilibrium conformational mixture at room temperature falls on twenty conformers belonging to five families: $\mathrm{G}^{\prime} \mathrm{T}, \mathrm{G}^{\prime} \mathrm{G}^{\prime}, \mathrm{GT}$, $\mathrm{GG}^{\prime}$ and $\mathrm{G}^{\prime} \mathrm{G}$ (Table 1). All of these conformers are + gauche $(\mathrm{G})$ or - gauche $\left(\mathrm{G}^{\prime}\right)$ with respect to the OCCO dihedral angle (see Fig. 1, where representatives of these families - the most stable form in each family - are depicted). Among the two gauche configurations around the OCCO dihedral angle, $\mathrm{G}^{\prime}$ is the most stable one. Conformers belonging to the $\mathrm{G}^{\prime} \mathrm{T}, \mathrm{G}^{\prime} \mathrm{G}^{\prime}$ and $\mathrm{G}^{\prime} \mathrm{G}$ families altogether represent more than $70 \%$ of 
Table 1 Relative calculated energies of conformers of 1,2-butanediol

\begin{tabular}{|c|c|c|c|c|c|c|c|}
\hline \multicolumn{3}{|c|}{ DFT(B3LYP) $/ 6-311++$ G(d,p) } & \multirow{3}{*}{$\begin{array}{l}\text { Family, } \\
\text { number }^{c}\end{array}$} & \multicolumn{4}{|c|}{$\mathrm{MP} 2 / 6-311++\mathrm{G}(\mathrm{d}, \mathrm{p})$} \\
\hline \multirow[b]{2}{*}{ Label } & \multirow{2}{*}{$\begin{array}{l}\text { Relative } \\
E_{e}+\mathrm{ZPE}^{a}\end{array}$} & \multirow{2}{*}{$\begin{array}{l}\text { Relative Gibbs } \\
\text { energy }^{b}\end{array}$} & & \multirow{2}{*}{$\begin{array}{l}\text { Relative } \\
E_{e}+\mathrm{ZPE}^{a}\end{array}$} & \multirow{2}{*}{$\begin{array}{l}\text { Relative } \\
\text { Gibbs energy }\end{array}$} & \multicolumn{2}{|c|}{ Populations } \\
\hline & & & & & & $298.15 \mathrm{~K}^{d}$ & $10 \mathrm{~K}^{c}$ \\
\hline & & & $\mathrm{G}^{\prime} \mathbf{T}$ & & & 46.42 & \\
\hline $\mathrm{tG}^{\prime} \mathrm{Tg}$ & 0.00 & 0.00 & 1 & 0.00 & 0.00 & 21.60 & 46.4 \\
\hline $\mathrm{gG}^{\prime} \mathrm{Tt}$ & 0.70 & 0.44 & 2 & 1.37 & 1.11 & 13.78 & 0 \\
\hline $\mathrm{g}^{\prime} \mathrm{G}^{\prime} \mathrm{Tg}$ & 1.64 & 1.91 & 3 & 2.18 & 2.56 & 7.68 & 0 \\
\hline \multirow[t]{2}{*}{$\mathrm{gG}^{\prime} \mathrm{Tg}^{\prime}$} & 3.21 & 3.49 & 10 & 4.27 & 4.61 & 3.36 & 0 \\
\hline & & & $\mathbf{G}^{\prime} \mathbf{G}^{\prime}$ & & & 16.20 & \\
\hline $\mathrm{gG}^{\prime} \mathrm{G}^{\prime} \mathrm{t}$ & 3.22 & 2.94 & 5 & 3.32 & 3.19 & 5.97 & 0 \\
\hline $\mathrm{tG}^{\prime} \mathrm{G}^{\prime} \mathrm{g}$ & 3.37 & 3.09 & 6 & 3.35 & 3.10 & 6.20 & 16.2 \\
\hline $\mathrm{g}^{\prime} \mathrm{G}^{\prime} \mathrm{G}^{\prime} \mathrm{g}$ & 4.85 & 4.80 & 14 & 5.49 & 5.42 & 2.43 & 0 \\
\hline \multirow[t]{2}{*}{$\mathrm{gG}^{\prime} \mathrm{G}^{\prime} \mathrm{g}^{\prime}$} & 5.32 & 5.32 & 16 & 6.07 & 6.44 & 1.61 & 0 \\
\hline & & & GT & & & 13.71 & \\
\hline $\mathrm{g}^{\prime} \mathrm{GTt}$ & 4.01 & 4.15 & 7 & 3.72 & 3.89 & 4.49 & 13.7 \\
\hline tGTg ${ }^{\prime}$ & 4.73 & 4.70 & 8 & 3.93 & 3.82 & 4.63 & 0 \\
\hline $\mathrm{g}^{\prime} \mathrm{GTg}$ & 5.24 & 5.37 & 11 & 4.76 & 4.82 & 3.09 & 0 \\
\hline \multirow[t]{2}{*}{$\mathrm{gGTg}^{\prime}$} & 6.35 & 6.64 & 18 & 6.43 & 6.62 & 1.50 & 0 \\
\hline & & & $\mathbf{G G}^{\prime}$ & & & 11.60 & \\
\hline $\mathrm{g}^{\prime} \mathrm{GG}^{\prime} \mathrm{t}$ & 4.42 & 4.47 & 4 & 2.87 & 3.10 & 6.18 & 11.6 \\
\hline $\mathrm{tGG}^{\prime} \mathrm{g}^{\prime}$ & 6.56 & 6.11 & 12 & 5.05 & 5.15 & 2.70 & 0 \\
\hline $\mathrm{g}^{\prime} \mathrm{GG}^{\prime} \mathrm{g}$ & 7.03 & 7.00 & 15 & 5.85 & 5.88 & 2.01 & 0 \\
\hline \multirow[t]{2}{*}{$\mathrm{gGG}^{\prime} \mathrm{g}^{\prime}$} & 8.55 & 8.29 & 19 & 8.44 & 8.48 & 0.71 & 0 \\
\hline & & & $\mathbf{G}^{\prime} \mathbf{G}$ & & & 8.10 & \\
\hline $\mathrm{tG}^{\prime} \mathrm{Gg}$ & 4.89 & 4.99 & 9 & 3.96 & 4.20 & 3.97 & 8.1 \\
\hline $\mathrm{gG}^{\prime} \mathrm{Gt}$ & 5.76 & 5.91 & 13 & 5.10 & 5.58 & 2.28 & 0 \\
\hline $\mathrm{g}^{\prime} \mathrm{G}^{\prime} \mathrm{Gg}$ & 6.56 & 7.00 & 17 & 6.13 & 6.70 & 1.45 & 0 \\
\hline \multirow[t]{2}{*}{$\mathrm{gG}^{\prime} \mathrm{Gg}^{\prime}$} & 9.25 & 9.52 & 20 & 9.55 & 9.89 & 0.40 & 0 \\
\hline & & & TT & & & & \\
\hline tTTg & 9.88 & 8.82 & 21 & 9.87 & 7.87 & 0.90 & \\
\hline tTTt & 9.84 & 8.48 & 22 & 10.25 & 8.61 & 0.67 & \\
\hline
\end{tabular}

${ }^{a}$ Relative electronic energies including zero-point vibrational energies $\left(E_{e}+\mathrm{ZPE}, \mathrm{kJ} \mathrm{mol}^{-1}\right)$. The lowest energy form is tG'Tg. Absolute $E_{e}+$ ZPE value calculated for this form is equal to $-308.848354 E_{\mathrm{h}}$ at the DFT level and to $-307.976595 E_{\mathrm{h}}$ at the MP2 level of theory. ${ }^{b}$ Relative electronic energies corrected for thermal free energies (relative Gibbs energy, $\mathrm{kJ} \mathrm{mol}^{-1}$ ). The lowest energy form is $\mathrm{tG}^{\prime} \mathrm{Tg}$. Absolute value of $\mathrm{Gibbs}$ free energy calculated for this form is equal to $-308.879707 E_{\mathrm{h}}$ at the DFT level and to $-308.007828 E_{\mathrm{h}}$ at the MP2 level of theory. ${ }^{c}$ Families are defined by the arrangements of the heavy-atom backbone. Numbers correspond to the order of relative energies, with zero-point vibrational energies included, calculated at the MP2/6-311+ $+\mathrm{G}(\mathrm{d}, \mathrm{p})$ level of theory. ${ }^{d}$ Conformational equilibrium populations characteristic of the gaseous phase at $298.15 \mathrm{~K}$ estimated on the basis of the Gibbs free energies calculated at the MP2 $/ 6-311++\mathrm{G}(\mathrm{d}$,p) level of theory. Values given in bold font correspond to the total population of the corresponding family of conformers. Fifteen higher energy conformers (relative energies $10-15 \mathrm{~kJ} \mathrm{~mol}^{-1}$ ) belonging to the GG, TT, TG and $\mathrm{TG}^{\prime}$ families, contribute to the equilibrium less than $2 \%$ total and were omitted from the table for brevity. ${ }^{e}$ Conformational populations of 1,2-butanediol expected to be trapped in a low temperature matrix at $10 \mathrm{~K}$.

conformational mixture at $298 \mathrm{~K}$. Evidently, with the OCCO fragment oriented as $\mathrm{G}^{\prime}$, the $\mathrm{O}(1) \mathrm{C}(1) \mathrm{C}(2) \mathrm{C}(3)$ dihedral angle assumes a trans orientation, thus decreasing the steric repulsion between the $\mathrm{O}(1) \mathrm{H}(1)$ group and the ethyl moiety and contributing to the stabilization of the $\mathrm{G}^{\prime} \mathrm{X}$ conformers with respect to the $\mathrm{GX}$ forms.

The CCCC dihedral angle determines the arrangement of the hydrocarbon chain. As expected, the more stable conformers adopt preferentially the trans configuration around this dihedral angle. More than $60 \%$ of the sampled conformers have a trans CCCC orientation (Table 1). The energy difference between the conformers with trans and gauche CCCC configurations is about $3 \mathrm{~kJ} \mathrm{~mol}^{-1}$.

If the equilibrium populations of the conformational families can be considered as a measure of their stabilities, then the stabilities of the different families, in terms of the OCCO and CCCC dihedral angles, are ordered as follows:

$$
\mathrm{G}^{\prime} \mathrm{T} \gg \mathrm{G}^{\prime} \mathrm{G}^{\prime}>\mathrm{GT}>\mathrm{GG}^{\prime}>\mathrm{G}^{\prime} \mathrm{G} \gg \mathrm{TT}
$$

With the exception of the TT family, all these structures are of $\mathrm{G}$ or $\mathrm{G}^{\prime}$ type with respect to the OCCO dihedral angle. Such orientation of the backbone brings the two $\mathrm{OH}$ groups to the closest possible distance. This, in turn, contributes to the establishment of the intramolecular $\mathrm{O}-\mathrm{H} \cdots \mathrm{O}$ interaction, which obviously has a stabilizing effect.

Each backbone structure includes conformers differing in the relative orientation of the $\mathrm{OH}$ groups. For the most stable $\mathrm{G}^{\prime} \mathrm{T}$ family, all possible $\mathrm{xG}^{\prime} \mathrm{Tx}$ structures were considered and only four different low energy minima were found. They are shown in Fig. 2. No other additional low energy minima (below $15 \mathrm{~kJ} \mathrm{~mol}^{-1}$ ) could be located on the potential energy surface of the $\mathrm{G}^{\prime} \mathrm{T}$ family. In all $\mathrm{G}^{\prime} \mathrm{X}$ families, the orientations of the $\mathrm{OH}$ groups were found to be the same: $\mathrm{tG}^{\prime} \mathrm{Xg}, \mathrm{gG}^{\prime} \mathrm{Xt}, \mathrm{g}^{\prime} \mathrm{G}^{\prime} \mathrm{Xg}$ and $\mathrm{gG}^{\prime} \mathrm{Xg}^{\prime}$. For the GX families of conformers, there are also four distinct patterns for orientation of the two $\mathrm{OH}$ groups: $\mathrm{g}^{\prime} \mathrm{GXt}$, $\mathrm{tGXg}^{\prime}, \mathrm{g}^{\prime} \mathrm{GXg}$ and $\mathrm{gGXg}$. Other possible combinations of the $\mathrm{CCOH}$ dihedral angles in the $\mathrm{G}^{\prime} \mathrm{X}$ and $\mathrm{GX}$ families are energetically much less favourable. Thus, only four conformers are of practical importance in both the $\mathrm{G}^{\prime} \mathrm{X}$ and $\mathrm{GX}$ families. The energy data for all these minima are given in Table 1 . 

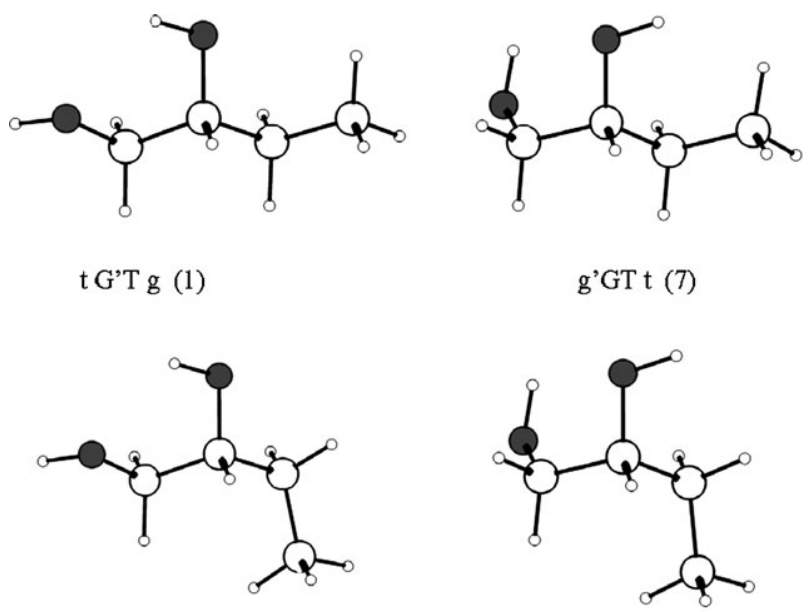

t G'G'g (6)

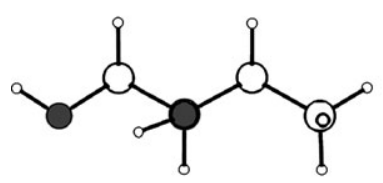

t G'T g (1)

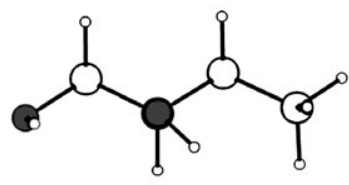

g G'T t (2)

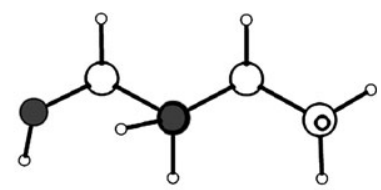

g'G'T g (3)

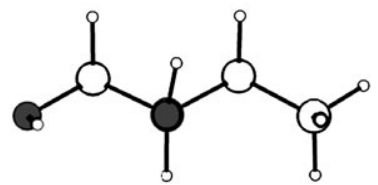

g G'Tg' (10)

Fig. 2 Three-dimensional structures of conformers belonging to the most stable $\mathrm{G}^{\prime} \mathrm{T}$ family. In all structures the $\mathrm{O}(2) \mathrm{C}(2)$ axis is perpendicular to the plane of the figure, $\mathrm{O}(2)$ atom eclipses $\mathrm{C}(2)$ atom and $\mathrm{C}(2) \mathrm{H}$ bond is oriented vertically downwards. Note that the structures differ only as to the orientation of the $\mathrm{OH}$ groups. Numbers in parentheses correspond to the relative energy order as calculated at the MP2/6-311+ $+\mathrm{G}(\mathrm{d}, \mathrm{p})$ level of theory.

strongest relaxant properties. ${ }^{13,14}$ Also the probability of conformational relaxation is related with the nature of the chemical groups undergoing intramolecular rearrangement. The smaller the size of the involved group, the easier it undergoes rearrangement. This effect becomes notable already with the substitution of the $\mathrm{O}-\mathrm{H}$ group by the $\mathrm{O}-\mathrm{CH}_{3}$ group. ${ }^{14}$ In our recent study of 2,3-butanediols ${ }^{1}$ we have shown that accounting for conformational cooling is of utmost importance for conformational characterization in matrices. For the two stereoisomers of 2,3-butanediol, $(R, S)$ and $(S, S)$, four conformational states are expected to be populated in the gaseous phase in detectable amounts, but only two of them, in each case, were experimentally observed in the low temperature matrices. The other two forms were separated from their lower energy counterparts by low energy barriers (less than $4 \mathrm{~kJ} \mathrm{~mol}^{-1}$ ) and could not be trapped in argon matrices at $10 \mathrm{~K}$. They underwent conformational cooling. ${ }^{1}$

\section{Low energy barriers}

In view of the importance of energy barriers for the interpretation of the experimental results, a detailed theoretical characterization of the barriers to intramolecular rotation has been carried out in this work for 1,2-butanediol. Special attention was paid to barriers converting higher energy species into their lower energy counterparts, in order to predict the accessibility of the barriers from the viewpoint of conformational cooling.

The 1,2-butanediol molecule involves three different types of intramolecular rotation related to $\mathrm{HOCC}, \mathrm{CCCC}$ and OCCO dihedral angles, and barriers for rotation around these dihedral angles were systematically investigated. Initially, calculations were carried out at the DFT(B3LYP)/6-311+ + G(d,p) level of theory. A chosen dihedral angle was incrementally changed, while all other geometrical parameters were optimized. Three typical potential energy profiles calculated in this way are shown in Fig. 3. In order to obtain more reliable 

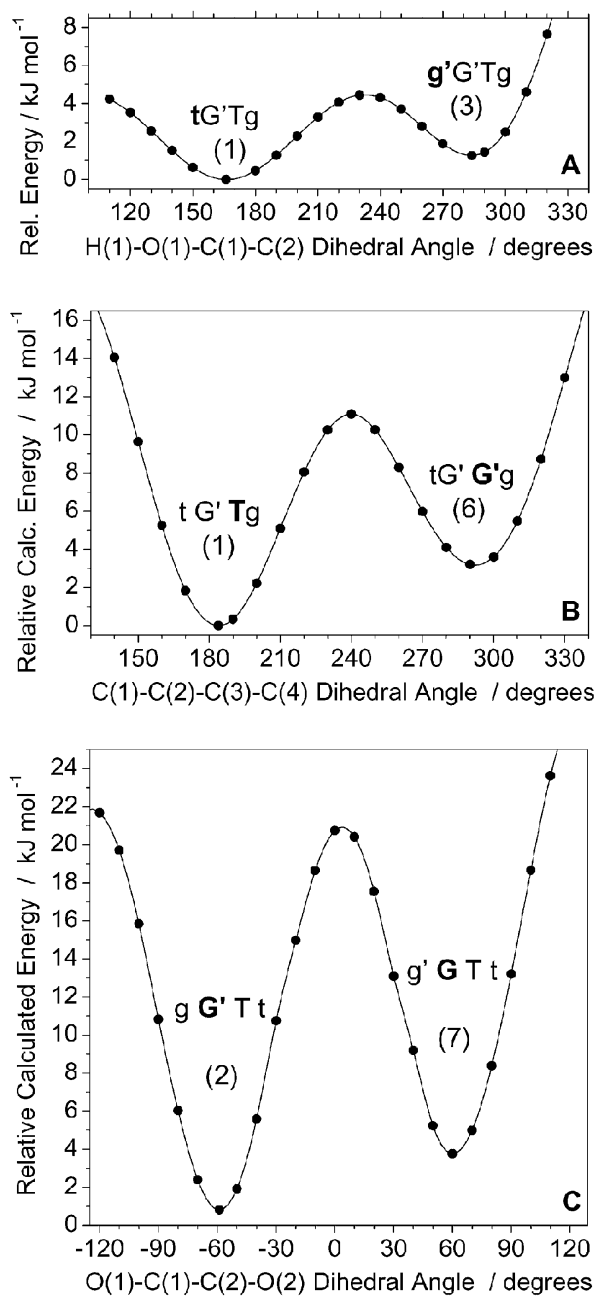

Fig. 3 Calculated DFT(B3LYP)/6-311+ $+\mathrm{G}(\mathrm{d}, \mathrm{p})$ potential energy profiles for three different types of intramolecular rotations in the molecule of 1,2-butanediol. Frames A, B, C (from top to bottom) show energy barriers for rotations around HOCC, CCCC and OCCO dihedral angles, respectively. Bold letters in conformer names correspond to the reaction coordinates. In all cases, the reaction coordinate was incrementally fixed while all other geometric parameters were fully relaxed at every point. Note, in frame $\mathrm{C}$, that the orientation around the HOCC axis changes from $\mathrm{g}^{\prime}(7)$ to $\mathrm{g}(2)$ simultaneously with the reaction coordinate, in such a way that the intramolecular hydrogen bond is conserved. Note also that linear ordinate scales are equal in all three frames. The zero energy level in all frames corresponds to the energy of the $\mathrm{tG}^{\prime} \mathrm{Tg}$ (1) conformer (without ZPE correction).

information about energies for conformational interconversions, additional calculations were carried out at the MP2/6$311++\mathrm{G}(\mathrm{d}, \mathrm{p})$ level, including geometry optimizations and calculations of the vibrational frequencies for all stationary points. The zero-point corrected values of barriers obtained in the MP2 calculations are summarized in Table 2.

At the MP2 level, the barriers for interconversions $3 \rightarrow 1$, $10 \rightarrow 2$ and $2 \rightarrow 1$ were found to be $1.1,3.1$ and $2.9 \mathrm{~kJ} \mathrm{~mol}^{-1}$, respectively (see Table 2). The very low barriers for rotation of the $\mathrm{OH}$ groups within the $\mathrm{G}^{\prime} \mathrm{T}$ family are expected to result in very effective conformational cooling. Such low barriers for rotation of the $\mathrm{OH}$ group can be easily surpassed in matrices at $10 \mathrm{~K},{ }^{15}$ according to our previous experimental observa- tions on other systems where intramolecular rotation of the $\mathrm{OH}$ groups may occur, like glycine, ${ }^{13}$ cyanoacetic acid ${ }^{14}$ and the two isomeric 2,3-butanediols. ${ }^{1}$ In the latter case, the values of the analogous barriers (calculated at the MP2/6$311++\mathrm{G}(\mathrm{d}, \mathrm{p})$ level) for the intramolecular rotations of the vicinal hydroxyl groups were very similar, all of them being less than $4.2 \mathrm{~kJ} \mathrm{~mol}^{-1}$. Thus, we can safely exclude conformers 2, 3 and 10 from the set of structures which are possibly retained in the matrix after deposition at $10 \mathrm{~K}$. Forms 2 and 3 should convert directly into form 1 , while form 10 converts into form 1 via form 2 as intermediate. This means that under the present experimental conditions, the $\mathrm{G}^{\prime} \mathrm{T}$ family is reduced in matrices exclusively to its most stable form ( $\mathrm{tG}^{\prime} \mathrm{Tg}$ ).

Calculations of the potential energy profiles for intramolecular rotations of the $\mathrm{OH}$ groups in the other relevant families of conformers gave results similar to that presented in frame A of Fig. 3. In particular, it was found that the conformers in all $\mathrm{G}^{\prime} \mathrm{X}$ and GX families are separated by low energy barriers (below $5 \mathrm{~kJ} \mathrm{~mol}^{-1}$, see Table 2) and every family is then expected to be reduced in the matrices to the corresponding lowest energy structure. The choice of the lowest energy structure, however, was not always straightforward, and deserves an additional comment.

According to the DFT calculations, the pair of conformers 5 and 6 (belonging to the $\mathrm{G}^{\prime} \mathrm{G}^{\prime}$ family), is separated in energy by only $0.15 \mathrm{~kJ} \mathrm{~mol}^{-1}$, and the MP2 calculations reduce this difference to a value as low as $0.03 \mathrm{~kJ} \mathrm{~mol}^{-1}$ ! A similar situation occurs in the GT family, for the pair of conformers 7 and 8. At the DFT level they are separated in energy by $0.7 \mathrm{~kJ} \mathrm{~mol}^{-1}$, the difference being reduced to $0.2 \mathrm{~kJ} \mathrm{~mol}^{-1}$ after the MP2 calculations. This means that calculations predict that forms 5 and 6 (and possibly also the pair 7 and 8) will be isoenergetical (see Table 1). However, these calculations apply to the vacuum. In a matrix, due to environment effects, a change in the relative energies of the conformers can occur, ${ }^{16}$ and it is difficult to predict a priori which of the forms will become more stable. The definite answer for the question of the most stable conformers in the families $\mathrm{G}^{\prime} \mathrm{G}^{\prime}(5$ or 6 ) and GT (7 or 8) can only be obtained from the experiment. At this stage, it is just important to note that the barriers between these forms are low enough to allow intramolecular interconversions between them (in both directions) in matrices at $10 \mathrm{~K}$. In practical terms, the results on the energy barriers described above mean that the twenty conformers populated in the gaseous phase at $298 \mathrm{~K}$ are expected to be reduced in matrices to only one conformer per family, ${ }^{17}$ due to low barriers to intramolecular rotation and effects of conformational cooling.

\section{Medium and high energy barriers}

Transformations between different families in the 1,2-BD molecule are realized via intramolecular rotation around the CCCC and OCCO dihedral angles.

Rotation of the methyl group around the CCCC axis interconnects structures within the $G^{\prime} X$ and GX families. One such barrier is presented in Fig. 3 (frame B). This is the barrier connecting forms 6 and 1 and it is the lowest among the barriers of this kind. At the DFT level, the energy barrier in direction $6 \rightarrow 1$ amounts to $c a .8 \mathrm{~kJ} \mathrm{~mol}^{-1}$, while a similar 
Table 2 Selected barriers for intramolecular rotation in 1,2-butanediol calculated at the MP2/6-311+ + G(d,p) level of theory ${ }^{a}$

\begin{tabular}{|c|c|c|c|c|c|c|c|c|c|c|c|c|}
\hline & & $\begin{array}{l}\text { Family } \\
\text { Number }\end{array}$ & $\begin{array}{l}\mathrm{G}^{\prime} \mathrm{T} \\
1\end{array}$ & $\begin{array}{l}\mathrm{G}^{\prime} \mathrm{T} \\
2\end{array}$ & $\begin{array}{l}\mathrm{G}^{\prime} \mathrm{T} \\
3\end{array}$ & $\begin{array}{l}\mathrm{G}^{\prime} \mathrm{T} \\
10\end{array}$ & $\begin{array}{l}\mathrm{G}^{\prime} \mathrm{G}^{\prime} \\
5\end{array}$ & $\begin{array}{l}\mathrm{G}^{\prime} \mathrm{G}^{\prime} \\
6\end{array}$ & $\begin{array}{l}\mathrm{G}^{\prime} \mathrm{G} \\
9\end{array}$ & $\begin{array}{l}\mathrm{GG}^{\prime} \\
4\end{array}$ & $\begin{array}{l}\text { GT } \\
7\end{array}$ & $\begin{array}{l}\text { GT } \\
8\end{array}$ \\
\hline Family & Number & & & & & & & & & & & \\
\hline $\mathrm{G}^{\prime} \mathrm{T}$ & 1 & & - & 4.3 & 3.3 & - & - & 12.5 & 19.9 & - & - & - \\
\hline $\mathrm{G}^{\prime} \mathrm{T}$ & 2 & & 2.9 & - & - & 6.0 & 12.9 & - & - & - & 22.1 & - \\
\hline $\mathrm{G}^{\prime} \mathrm{T}$ & 3 & & 1.1 & - & - & 11.0 & - & - & - & - & - & - \\
\hline $\mathrm{G}^{\prime} \mathrm{T}$ & 10 & & - & 3.1 & 9.0 & - & - & - & - & - & - & - \\
\hline $\mathrm{G}^{\prime} \mathrm{G}^{\prime}$ & 5 & & - & 10.9 & - & - & - & 4.6 & - & 26.5 & - & - \\
\hline $\mathrm{G}^{\prime} \mathrm{G}^{\prime}$ & 6 & & 9.1 & - & - & - & 4.6 & - & 20.9 & - & - & - \\
\hline $\mathrm{G}^{\prime} \mathrm{G}$ & 9 & & 16.0 & - & - & - & - & 20.3 & - & - & - & - \\
\hline $\mathrm{GG}^{\prime}$ & 4 & & - & - & - & - & 26.9 & - & - & - & 14.3 & - \\
\hline GT & 7 & & - & 19.8 & - & - & - & - & - & 13.4 & - & 4.8 \\
\hline GT & 8 & & - & - & - & - & - & - & - & - & 4.6 & - \\
\hline
\end{tabular}

${ }^{a}$ Relative energies (in $\mathrm{kJ} \mathrm{mol}^{-1}$ ), including zero point vibrational energy contributions. Families and numbers of conformers correspond to those presented in Table 1. The reactant species are indicated in the left column, while the products - in the headline. Groups of cells highlighted by bold characters show the conformers belonging to the same family.

calculation at the MP2 level gives the value of $c a .9 \mathrm{~kJ} \mathrm{~mol}^{-1}$ for this barrier (Table 2). Even so, it is at least twice as high when compared to the barriers for rotations of the hydroxyl groups.

In view of the uncertainty as regards which of the forms in the $\mathrm{G}^{\prime} \mathrm{G}^{\prime}$ family (5 or 6 ) is the most stable in the matrices, a similar barrier calculation was carried out for the pair of forms 5 and 2. It resulted in similar energy barrier values: 9.4 and $10.9 \mathrm{~kJ} \mathrm{~mol}^{-1}$ at the DFT and MP2 levels, respectively. Thus, for any of the pairs, $5 \rightarrow 2$ or $6 \rightarrow 1$, the intramolecular rotation connects one of the two most stable forms of the $\mathrm{G}^{\prime} \mathrm{G}^{\prime}$ family with one of the two most stable forms of the $\mathrm{G}^{\prime} \mathrm{T}$ family. To occur, such transformation (with the internal rotation of the methyl group and a barrier of $c a .10 \mathrm{~kJ} \mathrm{~mol}^{-1}$ ) can be expected to require a temperature that is in the range of the experimentally accessible temperatures of our matrix isolation apparatus. For example, such a transformation (with a calculated barrier of $10 \mathrm{~kJ} \mathrm{~mol}^{-1}$ ) was experimentally observed occurring between 30 and $40 \mathrm{~K}$ for matrix-isolated trimethylphosphate. ${ }^{18}$ Another similar transformation, with a barrier of $c a .9 \mathrm{~kJ} \mathrm{~mol}^{-1}$, was found to be thermally activated in matrices between 30 and $36 \mathrm{~K}$ for 1,2-difluoroethane. ${ }^{19}$

An analogous transformation between the most stable forms of the GT and $\mathrm{GG}^{\prime}$ families (7 and 4) has slightly higher predicted energy barrier values: 12.1 and $13.4 \mathrm{~kJ} \mathrm{~mol}^{-1}$ at the DFT and MP2 levels, respectively. Finally, the highest predicted barriers for the rotation around the CCCC axis separate $9\left(\mathrm{G}^{\prime} \mathrm{G}\right.$ family) from its counterparts $6\left(\mathrm{G}^{\prime} \mathrm{G}^{\prime}\right)$ and $1\left(\mathrm{G}^{\prime} \mathrm{T}\right)$. In the direction $9 \rightarrow 1$, the calculated height of the barrier is 14.1 and $16.0 \mathrm{~kJ} \mathrm{~mol}^{-1}$ at the DFT and MP2 levels, respectively. According to the calculated barriers, the conversions $5 \rightarrow 2$ or $6 \rightarrow 1$ should then occur in matrices first, while the transformation $7 \rightarrow 4$ should be expected to take place at slightly higher temperatures, and be followed by the transformation $9 \rightarrow 1$.

The third kind of intramolecular rotation in 1,2-BD is related to the change of the OCCO dihedral angle. A typical energy profile for such rotation is presented in frame $\mathrm{C}$ of Fig. 3. The interconversions of practical interest are those associated with the pairs $(4,5)$ and $(2,7)$. The DFT calculations predict these barriers to be $c a .23$ and $17 \mathrm{~kJ} \mathrm{~mol}^{-1}$, respectively. The MP2 calculations increase these values to 26.5 and $19.8 \mathrm{~kJ} \mathrm{~mol}^{-1}$. These are very high barriers, and provided such transformation could take place in a matrix, it is expected to occur at rather elevated temperatures. The calculated values of barriers for the OCCO rotation in 1,2-BD are in accordance with the analogous barriers calculated for 2,3-butanediol, which at the DFT level were found to be 27 and $18 \mathrm{~kJ} \mathrm{~mol}^{-1}{ }^{1}$ The corresponding transformations were not experimentally observed in the latter case.

Summarizing, the intramolecular rotations around the CCCC and OCCO axes involve medium and high barriers. On the basis of comparison with available experimental data, these barriers are high enough to allow the local minima 4 $\left(\mathrm{GG}^{\prime}\right), 5$ or $6\left(\mathrm{G}^{\prime} \mathrm{G}^{\prime}\right), 7$ or $8(\mathrm{GT})$ and $9\left(\mathrm{G}^{\prime} \mathrm{G}\right)$, along with the lowest energy form $1\left(\mathrm{G}^{\prime} \mathrm{T}\right)$, to be trapped in matrices if the samples of 1,2-butanediol are deposited at low temperatures of the optical substrate ( $\mathrm{ca} .10 \mathrm{~K}$ ). On the other hand, it could be anticipated that at least some of these conformers will convert to lower energy forms upon annealing of the matrices to a higher accessible temperature.

\section{Interpretation of the vibrational spectra}

In order to interpret the experimental spectra, we used a series of assumptions and the analysis of the theoretically calculated spectra. First, analysis was reduced to twenty-two conformers responsible for $98 \%$ of gaseous phase equilibrium at room temperature (see Table 1). Second, it was assumed that the energy barriers above $10 \mathrm{~kJ} \mathrm{~mol}^{-1}$ (rotations around $\mathrm{CCCC}$ and OCCO angles) could not be surpassed during deposition of the samples at $10 \mathrm{~K}$. This means that the population of each family corresponds to its weight at gas phase equilibrium. Third, it was assumed that barriers below $5 \mathrm{~kJ} \mathrm{~mol}^{-1}$ (rotations around HOCC angles) are low enough and can be effectively overcome during deposition. Thus each family is represented in the freshly deposited matrix by its most stable conformer, as it was explained above.

The choice of the most stable structures was straightforward for the $\mathrm{G}^{\prime} \mathrm{T}, \mathrm{GG}^{\prime}$ and $\mathrm{G}^{\prime} \mathrm{G}$ families. These are forms 1,4 and 9 , respectively. The ambiguity still remained in two pairs: for forms 5 or 6 in the $G^{\prime} G^{\prime}$ family, and 7 or 8 in the GT family. In these two pairs, each structure was tried as a possible alternative for the most stable representative of the corresponding family, as well as their mixture in equal amounts. The best fit 
of the simulated spectrum with the experimental data was achieved when forms 6 and 7 were used as representatives of the $\mathrm{G}^{\prime} \mathrm{G}^{\prime}$ and $\mathrm{GT}$ families in the matrix. This means that under the present experimental conditions form 6 is energetically more stable than form 5 , and form 7 is more stable than form 8 , as evidenced by the experimental spectra. The change in relative stabilities is perhaps a common phenomenon for molecules of vicinal alcohols isolated in low temperatures in matrices. For, example, infrared spectroscopy studies on 1,2ethanediol carried out in a low-temperature argon matrix $(18 \mathrm{~K})$ detected experimentally two forms ( $\mathrm{tGg}^{\prime}$ and $\mathrm{gGg}^{\prime}$ ) trapped in the matrix ${ }^{20}$ instead of one form which would be expected on the basis of their energy difference obtained from theoretical calculations.

The theoretical spectrum of a mixture of conformers $1,6,7$, 4 and 9, with contributions of 46.4, 16.2, 13.7, 11.6 and 8.1\%, respectively, is shown in Fig. 4 (upper frame). This spectrum simulates a freshly deposited matrix where the first stage of the conformational cooling, i.e. relaxation around the HOCC dihedral angles, has already occurred. This spectrum is compared to the experimental spectrum of 1,2-BD isolated in a krypton matrix at $10 \mathrm{~K}$ in Fig. 4 (middle frame). The lower frame of Fig. 4 shows an alternative simulated spectrum constructed as a superposition of the spectra due to the twenty-two most stable forms, representing more than $98 \%$ of the gas phase equilibrium (presuming the absence of conformational cooling). Clearly, the theoretical spectrum composed of five forms better resembles the experimental one. In view of the complexity of the studied system, and also because of the number of effects which are difficult to simulate (e.g. site-splitting of the absorption bands, or weak spectral signals ${ }^{21}$ ), the agreement between the theory and experiment can be considered as fairly good. The close match of the experimental and theoretical spectra proves the ability of the applied theoretical approach to predict the conformational equilibrium of simple intramolecular $\mathrm{H}$-bonded systems as the vicinal butanediols.

Additional evidence in favor of the adopted interpretation is provided by the results of annealing of the matrices. In order to analyze changes in the experimental spectra, the annealing was simulated theoretically. Fig. 5 represents selected regions of the simulated theoretical spectra due to conformers 1, 6, 7, 4 and 9 shown as separate traces. It shows also two different sums of these individual spectra. One of these sums (upper trace, thin line) corresponds to the spectrum of a freshly deposited matrix and is equal to the spectrum named as "5 forms" in Fig. 4. Another spectrum (upper trace, bold line) contains contributions only due to forms 1, 7, 4 and 9 where the population of form 1 is augmented at the expense of the population due to form 6 . This pair of spectra simulates theoretically the conversion $6 \rightarrow 1$.

Annealing of xenon matrices up to $30 \mathrm{~K}$ resulted in the spectral changes represented in upper frame of Fig. 6. These changes agree quite well with the simulated annealing of form 6 (Fig. 6, lower frame). It is especially interesting to note that in the regions where strong absorptions due to form 5 are expected (e.g. around $1260 \mathrm{~cm}^{-1}$, see Figs. 5A and 6A), the spectral changes in the annealing experiment are very small. These observations provide experimental evidence for the higher stability of form 6 relative to form 5 in matrices.

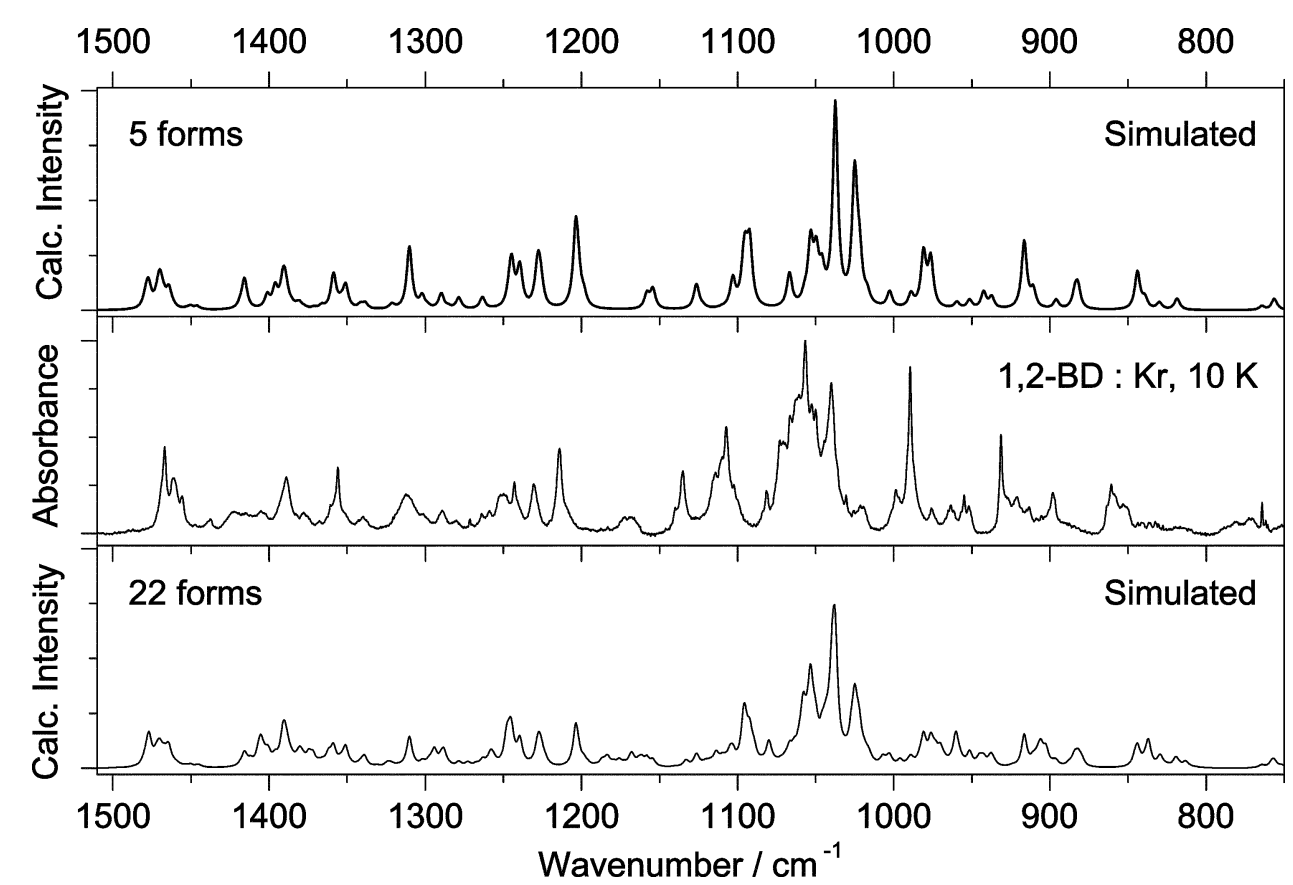

Fig. 4 Fingerprint region of the experimental infrared spectrum of 1,2-butanediol isolated in a krypton matrix at $10 \mathrm{~K}$ (middle frame) compared to two theoretically simulated spectra. The spectrum in the upper frame contains contributions of five conformers: (1), (4), (6), (7), and (9). The spectrum in the lower frame contains contributions of the twenty-two lowest energy forms. Intensities due to conformers are population-weighted, as described in the text. All frequencies were calculated at the DFT(B3LYP)/6-311+ + G(d,p) level of theory and scaled by a factor of 0.978 . Calculated spectra were simulated using Lorentzian functions centered at the calculated (scaled) frequencies and with bandwidth-at-half height equal to $4 \mathrm{~cm}^{-1}$. Linear ordinate scales in the simulated spectra are equal. 

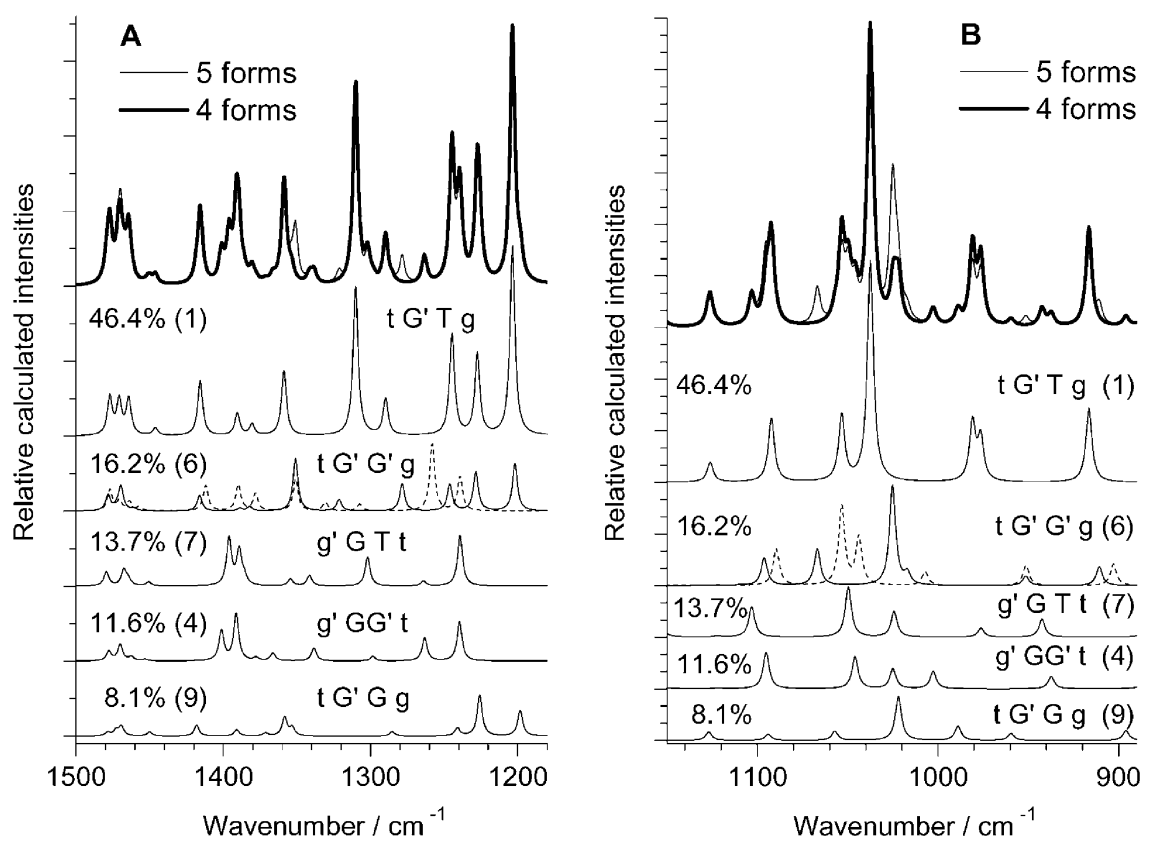

Fig. 5 Fingerprint region of the infrared spectra of selected 1,2-butanediol conformers calculated at the DFT(B3LYP)/6-311+ + G(d,p) level of theory. Five lower traces represent spectra of individual conformers (1), (6), (7), (4) and (9), with their intensities reduced to the contributions of the respective families (in \%) in the equilibrium mixture at $298 \mathrm{~K}$. The spectra are shifted along the ordinate scale for clarity. Two upper traces represent: "5 forms" (thin line) - superposition of spectra (1), (6), (7), (4) and (9) simulating the spectrum of a freshly deposited matrix; "4 forms" (bold line) - superposition of spectra (1), (7), (4) and (9) where the population due to form (6) is eliminated in favor of form (1). The latter spectrum simulates the first step of annealing. All calculated frequencies are scaled by a factor of 0.978 . Calculated spectra were simulated using Lorentzian functions centered at the calculated (scaled) frequencies and with bandwidth-at-half height equal to $4 \mathrm{~cm}^{-1}$. The dashed line represents the calculated spectrum due to conformer $\mathrm{gG}^{\prime} \mathrm{G}^{\prime} \mathrm{t}(5)$ in the same abundance $(16.2 \%)$ as that of conformer $\mathrm{tG}^{\prime} \mathrm{G}^{\prime} \mathrm{g}(6)$. Note the change of the ordinate scale from frame A to frame B.
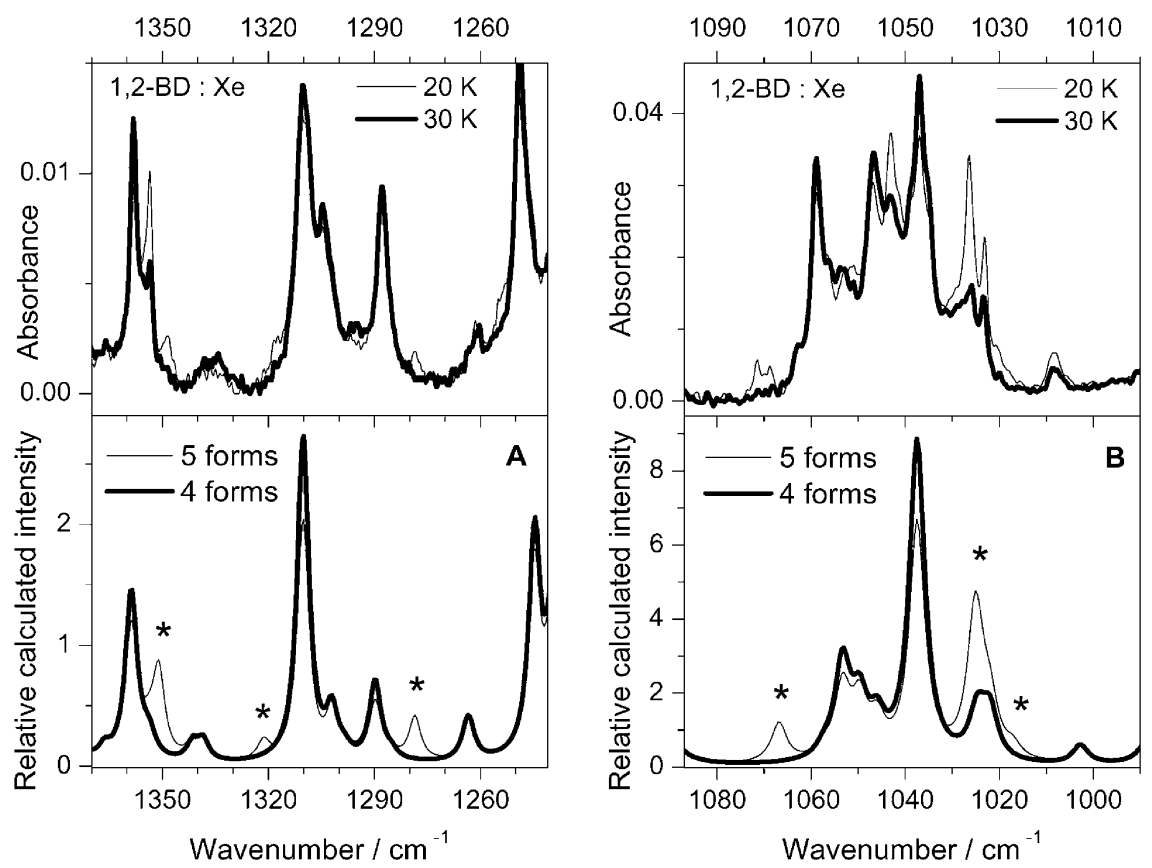

Fig. 6 Selected regions of the infrared spectrum of 1,2-butanediol. Upper frames: experimental spectra of the compound isolated in a xenon matrix at $20 \mathrm{~K}$ (thin line) and after annealing of this sample to $30 \mathrm{~K}$ (bold line). Lower frames represent theoretically calculated spectra: " 5 forms" (thin line) - superposition of spectra (1), (6), (7), (4) and (9) simulating the spectrum of a freshly deposited matrix; "4 forms" (bold line) - superposition of spectra (1), (7), (4) and (9) where the population due to form (6) is eliminated in favor of form (1). The latter spectrum simulates the first step of annealing. Asterisks designate positions of bands due to conformer (6). The split of the theoretical spectra into individual components is shown in Fig. 5. Please refer to the caption of Fig. 5 for other details. 


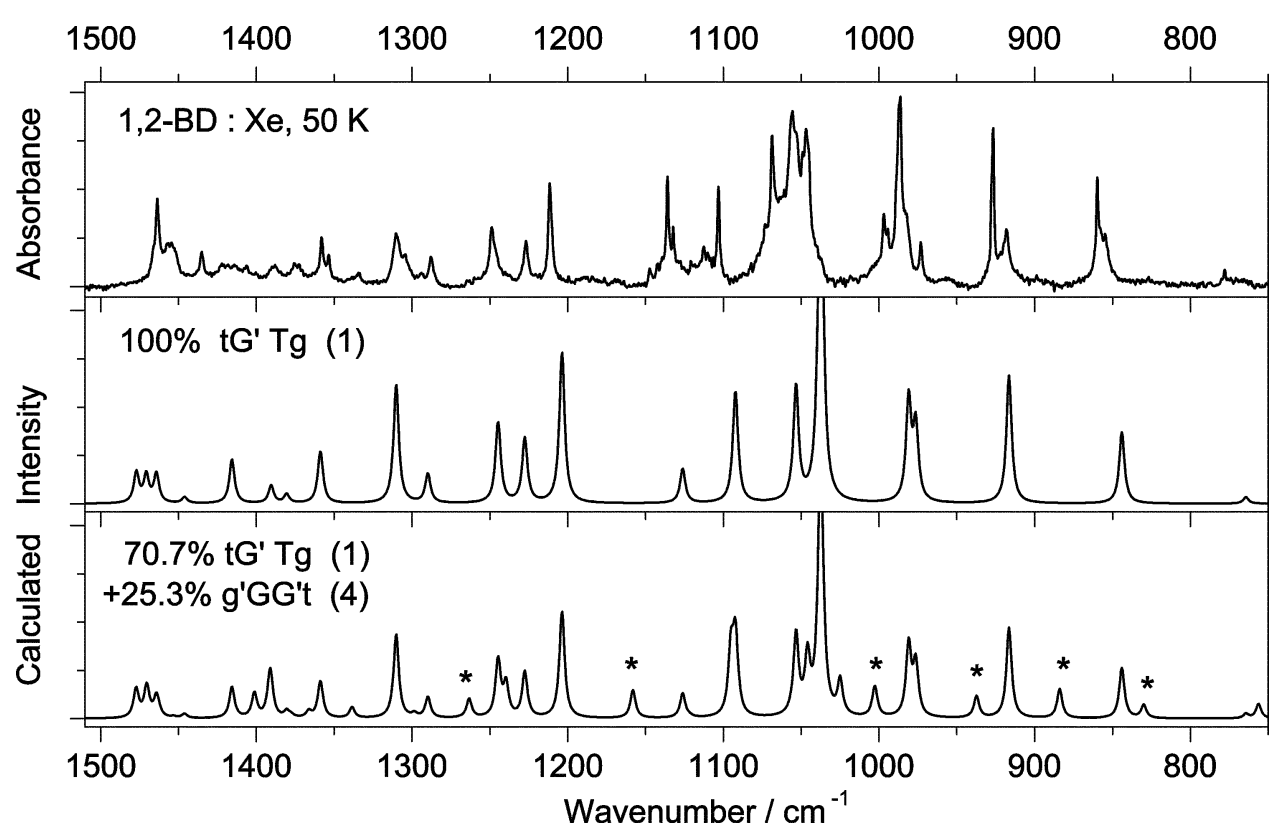

Fig. 7 The fingerprint region of the experimental infrared spectrum of 1,2-butanediol isolated in a xenon matrix (upper frame) after annealing of the sample to $50 \mathrm{~K}$ compared to the theoretically simulated spectrum of conformer $1(100 \%)$ (middle frame), and to the theoretically simulated spectrum of a mixture of conformers 1 (70.7\%) and 4 (25.3\%) (lower frame). Asterisks designate bands due to conformer 4 , which do not have counterparts in the experimental spectrum. All frequencies were calculated at the DFT(B3LYP)/6-311+ + G(d,p) level of theory and scaled by a factor of 0.978. Calculated spectra were simulated using Lorentzian functions centered at the calculated (scaled) frequencies and with bandwidthat-half height equal to $4 \mathrm{~cm}^{-1}$.

The energy required for transformation $6 \rightarrow 1$, according to the calculations, is $c a .9 \mathrm{~kJ} \mathrm{~mol}^{-1}$. Beside form 6 , there are three more local minima (4, 7 and 9) which according to the adopted theoretical model still remain in matrix. The corresponding barriers related to the transformations of forms 7 and 9 into lower energy forms are $13.4 \mathrm{~kJ} \mathrm{~mol}^{-1}(7 \rightarrow 4)$ and $16 \mathrm{~kJ} \mathrm{~mol}^{-1}(9 \rightarrow 1)$, respectively (Table 2$)$ and require only rotation around the CCCC dihedral angle in each case, similarly to the process $6 \rightarrow 1$. Therefore, it appears possible that these two processes could also take place in xenon matrices upon annealing to a higher temperature. Assuming then the possibility of the occurrence of these two isomerization processes, upon annealing of the xenon matrices up to $c a$. $50 \mathrm{~K}$, all $\mathrm{G}^{\prime} \mathrm{X}$ conformers $(9,6$ and 1$)$ would accumulate as the most stable form $1\left(\mathrm{G}^{\prime} \mathrm{T}\right)$, and all $\mathrm{GX}$ conformers (7 and 4) would accumulate as the most stable conformer 4 . The composition of the target sample could then be expected to be $70.7 \%$ of form 1 and $25.3 \%$ of form 4 (the remaining $4 \%$, which according to the calculations are distributed between other forms, mainly TT family, were neglected).

The experiment exceeded our expectations. Not only did forms 9 and 7 disappear from the sample, but form 4 did so too. Fig. 7 represents the experimental FTIR spectrum of 1,2$\mathrm{BD}$ in a xenon matrix annealed up to $50 \mathrm{~K}$ (upper frame). This spectrum is compared to a theoretically simulated "anticipated" spectrum (lower frame) obtained as a mixture of forms 4 and 1. A simulated theoretical spectrum of pure form 1 is also shown for comparison (middle frame). The experimental spectrum (upper frame) corresponds better to the spectrum of a pure form 1, rather than to the mixture of two forms. In the simulated spectrum of the mixture, there is a series of absorp- tions due to form 4 (marked by asterisks) that are clearly absent in the experiment. From the registration of the spectrum at intermediate temperatures, there was an indication that the observed annealing, with the complete transformation of all forms into form 1, was essentially completed up to $40 \mathrm{~K}$.

The reasons for the disappearance of form 4 upon annealing of the xenon matrix are not obvious. Indeed, form 4 belongs to the $\mathrm{GG}^{\prime}$ (or GX) family and its conversion to a form of the $\mathrm{G}^{\prime} \mathrm{X}$ family requires the change of the OCCO dihedral angle. This type of conversion is related with the highest barriers in 1,2-BD. For example, form 4 is separated from form $5\left(\mathrm{G}^{\prime} \mathrm{G}^{\prime}\right.$ family) by a barrier of $26.9 \mathrm{~kJ} \mathrm{~mol}^{-1}$. In order to overcome such a barrier, the sample would require heating to a temperature of about $75 \mathrm{~K}$. This temperature is too high compared to the conditions of the present experimental study. There is an alternative possibility for conformer 4 to undergo transformation into a form belonging to a $\mathrm{G}^{\prime} \mathrm{X}$ family. It involves a series of steps. Firstly, transformation $4 \rightarrow 7$ occurs, which is related to the rotation around the CCCC axis and a moderate barrier of $14.3 \mathrm{~kJ} \mathrm{~mol}^{-1}$. Secondly, form 7 (GT family) undergoes rotation around the OCCO angle and converts to form 2 (the most stable $\mathrm{G}^{\prime} \mathrm{T}$ family). The barrier at this stage is calculated to be $19.8 \mathrm{~kJ} \mathrm{~mol}^{-1}$, which can be related to the temperature of $55 \mathrm{~K}$. Finally, form 2 easily converts to form 1, as was explained in detail above. This mechanism already requires a moderate temperature, but is still well above $40 \mathrm{~K}$. A possible explanation is that the matrix environment lowers the region between the first order saddle points (by few $\mathrm{kJ} \mathrm{mol}^{-1}$ ), essentially destroying them in favour of one or more new ones and making the observed transformations energetically accessible. 
There is an interesting comparison with the molecule of 2,3-butanediol. This molecule was shown ${ }^{1}$ to have the pair of most stable forms, $\mathrm{tGg}^{\prime}$ and $\mathrm{tG}^{\prime} \mathrm{g}$, separated by a barrier of $18 \mathrm{~kJ} \mathrm{~mol}^{-1}$. That barrier could not be surpassed even after annealing of xenon matrices up to $65 \mathrm{~K}$. And there was only one internal coordinate separating the two forms in 2,3butanediol, namely the OCCO dihedral angle. No alternative pathways could be conceived to transform one form into another. The barrier of a similar height $\left(19.8 \mathrm{~kJ} \mathrm{~mol}^{-1}\right)$ conjugated with another barrier $\left(14.3 \mathrm{~kJ} \mathrm{~mol}^{-1}\right)$ could however be successfully overcome in 1,2-butanediol at temperatures below $50 \mathrm{~K}$. This experimental observation stresses the importance of environment-induced changes to the potential energy surface of the studied system in lowering the energy of the observed intramolecular transformation.

\section{Experimental}

Commercial $( \pm$ )-1,2-BD (Aldrich, $+99 \%$ ) was used in the present study. The purity of the compound was checked by GLC and was equal to $99.6 \pm 0.2 \%$. Due to its high hygroscopicity the compound was transferred from the factory packing into the effusive cell in a glove-box under dry nitrogen atmosphere. An effusive Knudsen cell ${ }^{10}$ was equipped with a SS-4BMRG (NUPRO) needle valve with a shut-off possibility which prevented the sample coming into contact with the atmosphere before the experiments. Prior to the experiment, the cell was connected to the vacuum system of the cryostat and the compound was additionally purified from dissolved gases by pumping through the cryostat. The two parts of the effusive cell, the valve nozzle and the sample compartment, were thermostatted separately. During deposition, the sample compartment was cooled to $0{ }^{\circ} \mathrm{C}$ by immersing the ampoule with the compound in a bath with melting water-ice mixture. This allowed the saturated vapor pressure over the compound to be reduced and the metering function of the valve to be improved. The valve nozzle was kept at room temperature $(298 \mathrm{~K})$ and this temperature defined the equilibrium ratio of butanediol conformers in the vapor before deposition.

The deposition rate of the compound was chosen to be low enough to ensure that the species trapped in the matrices were mainly monomers. A CsI window was used as optical substrate for the matrices. Its temperature was stabilized and measured directly at the sample holder by a silicon diode sensor connected to a digital controller (Scientific Instruments, Model 9650-1), with accuracy of $0.1 \mathrm{~K}$.

A glass vacuum system and standard manometric procedures were applied to deposit matrix gases (argon N60, krypton N48 and xenon N45, all supplied by Air Liquide), which were used without further purification. The low-temperature equipment was based on a closed-cycle helium refrigerator (APD Cryogenics) with a DE-202A expander. The infrared spectra were registered with resolution of $0.5 \mathrm{~cm}^{-1}$, in the range $4000-400 \mathrm{~cm}^{-1}$, using a Mattson (Infinity 60AR Series) Fourier transform spectrometer equipped with a deuterated triglycine sulfate (DTGS) detector and a $\mathrm{KBr}$ beamsplitter. The sample compartment of the spectrometer was modified in order to couple it with the cryostat head and allow purging of the instrument by a stream of dry nitrogen to remove carbon dioxide and water vapors.

\section{Computational method}

As was mentioned in the Introduction, 1,2-BD has a large number of a priori relevant conformations (81). This means that the exploration of all possible forms, using high level theoretical methods, will be computationally very expensive. Hence, for this molecule, a random conformational search method, followed by full molecular mechanics minimization using the CFF91 force field, ${ }^{11}$ was undertaken to obtain a reasonable sampling of the most important structures. This procedure was similar to that applied in a previous study on this compound. ${ }^{9}$ However, the range of the sampled structures was extended in this work to cover the conformations of 1,2BD with relative energies within $c a .15 \mathrm{~kJ} \mathrm{~mol}^{-1}$ above the global minimum. These structures were then fully optimised at the DFT(B3LYP) level of approximation ${ }^{22}$ as well as at the MP2 level of theory ${ }^{23}$ with the standard $6-311++\mathrm{G}(\mathrm{d}, \mathrm{p})$ basis set. $^{24}$ The DFT and MP2 calculations were performed using the GAUSSIAN 98 program package. ${ }^{25}$

An important part of this study was the calculation of the barriers to intramolecular rotation and characterisation of the transition states. The geometries of the transition states were optimized using the synchronous transit-guided quasi-Newton (STQN) method with the quadratic synchronous transit (QST) approach, ${ }^{26}$ in its QST2 variety. After geometry optimization, calculation of the harmonic vibrational frequencies was carried out at the same level of theory to characterize the nature of each stationary point. The structures exhibiting one imaginary frequency in the calculated spectrum were characterized as first-order saddle points. The calculated IR spectra were also used to assist in the interpretation of the experimental spectra and to account for the zero-point vibrational energy (ZPE) contribution.

\section{Conclusion}

A detailed study of the potential energy surface for the 1,2butanediol molecule (calculated both at the DFT and MP2 level of theory) enabled the gas phase equilibrium at room temperature to be characterized and the conformational cooling occurring in the system in the cryogenic matrices to be understood. It was found that the conformers of 1,2-BD may be classified into several families, each of them with a specific configuration of the heavy atom backbone determining their characteristic conformational behaviour. Barriers to intramolecular rotation within every family do not exceed $5 \mathrm{~kJ} \mathrm{~mol}^{-1}$. These barriers are readily surpassed during deposition of 1,2BD into a matrix (due to the conformational cooling) and only five conformers, the most stable representatives of each family, are retained in the samples at $10 \mathrm{~K}$. When the samples were heated to temperatures around $30 \mathrm{~K}$, as expected, interconversions between different families occurred, involving crossing of low or moderate energy barriers. Annealing of the xenon matrices up to $50 \mathrm{~K}$ resulted in depopulation of all conformational states into the most stable one.

The present study is a frequent case for the matrix isolation experiment carried out on a conformationally flexible 
molecule, where many conformations contribute appreciably to the gas phase equilibrium. When such a system is frozen into a matrix, as a rule, the same conformations that are characteristic of gas are trapped in the sample. The latter case therefore represents a non-equilibrium situation, usually without the possibility of reaching thermodynamic equilibrium in the sample. The singularity of the present study is that the studied system is capable of overcoming ALL energy barriers and arriving at true thermodynamic conformational equilibrium, while the studied compound is still embedded in the matrix. So, the present experiment goes through a sequence:

$$
\begin{aligned}
& \text { equilibrium (gas) } \\
& \text { non-equilibrium (matrix) } \\
& \text { equilibrium (matrix) }
\end{aligned}
$$

This is a very unusual, paradigmatic case in matrix isolation studies dealing with molecules of this size and complexity.

\section{Acknowledgements}

This work was financially supported by "Fundação para a Ciência e a Tecnologia" (FCT - Project POCTI/QUI/59019/ 2004, also supported by FEDER), FCT Grants SFRH/BPD/ 1661/2000 and SFRH/BD/9110/2002 and the "Instituto de Investigação Interdisciplinar da Universidade de Coimbra" (Project III/BIO/40/2005).

\section{References}

1 A. J. Lopes Jesus, M. T. S. Rosado, I. Reva, R. Fausto, M. E. Eusébio and J. S. Redinha, J. Phys. Chem. A, 2006, 110, 4169-4179.

2 (a) H. Piekarski, M. Jozwiak, J. Woznicka, A. Bald and A. Szejgis, Phys. Chem. Liq., 1995, 30, 195-207; (b) H. Piekarski and A. Pietrzak, J. Mol. Liq., 2005, 121, 46-52; (c) C. Kracht, P. Ulbig and S. Schulz, Thermochim. Acta, 1999, 337, 209-217; (d) C. Kracht, P. Ulbig and S. Schulz, J. Chem. Thermodyn., 1999, 31, 1113-1127; (e) H. Geyer, P. Ulbig and M. Gornert, J. Chem. Thermodyn., 2000, 32, 1585-1596; (f) H. Iloukhani and H. Bahrami, Phys. Chem. Liq., 2000, 38, 103-111; (g) H. Geyer, P. Ulbig, M. Gornert and A. Susanto, J. Chem. Thermodyn., 2001, 33, 987-997; (h) J. George and N. V. Sastry, J. Chem. Eng. Data, 2003, 48, 1529-1539; (i) M. Fujisawa, T. Matsushita, Y. Matsui, K. Akasaka and T. Kimura, J. Therm. Anal. Calorim., 2004, 77, 225-231; (j) S. P. Verevkin, Fluid Phase Equilib., 2004, 224, 23-29.

3 E. Fishman and T. L. Chen, Spectrochim. Acta, Section A: Mol. Spectrosc., 1969, 25, 1231-1242.

4 A. B. Foster, A. H. Haines and M. Stacey, Tetrahedron, 1961, 16, 177.

5 W. M. Coleman and B. M. Gordon, Appl. Spectrosc., 1988, 42, 671-674.

6 F. B. Gallwey, J. E. Hawkes, P. Haycock and D. Lewis, J. Chem. Soc., Perkin Trans. 2, 1990, 1979-1985.

7 M. van Duin, J. M. A. Baas and B. van de Graaf, J. Org. Chem., 1986, 51, 1298-1302.

8 (a) S. Vazquez, R. A. Mosquera, M. A. Rios and C. van Alsenoy, J. Mol. Struct. THEOCHEM), 1989, 184, 323-342; (b) S. Reiling,
J. Brickmann, M. Schlenkrich and P. A. Bopp, J. Comput. Chem., 1996, 17, 133-147.

9 A. J. Lopes Jesus, M. T. S. Rosado, M. L. P. Leitão and J. S. Redinha, J. Phys. Chem. A, 2003, 107, 3891-3897.

10 I. D. Reva, S. G. Stepanian, L. Adamowicz and R. Fausto, J. Phys. Chem. A, 2001, 105, 4773-4780.

11 (a) J. R. Maple, U. Dinur and A. T. Hagler, Proc. Natl. Acad. Sci. U. S. A., 1988, 85, 5350-5354; (b) M. J. Hwang, T. P. Stockfisch and A. T. Hagler, J. Am. Chem. Soc., 1994, 116, 2515-2525.

12 A. J. Barnes, J. Mol. Struct., 1984, 113, 161-174.

13 I. D. Reva, A. M. Plokhotnichenko, S. G. Stepanian, A. Y. Ivanov, E. D. Radchenko, G. G. Sheina and Y. P. Blagoi, Chem. Phys. Lett., 1995, 232, 141-148; I. D. Reva, A. M. Plokhotnichenko, S. G. Stepanian, A. Y. Ivanov, E. D. Radchenko, G. G. Sheina and Y. P. Blagoi, Chem. Phys. Lett., 1995, 235, 617.

14 I. D. Reva, S. G. Stepanian, L. Adamowicz and R. Fausto, Chem. Phys. Lett., 2003, 374, 631-638.

15 Temperatures lower than $10 \mathrm{~K}$ are not accessible in our experimental setup.

16 S. Coussan, Y. Bouteiller, J. P. Perchard and W. Q. Zheng, J. Phys. Chem. A, 1998, 102, 5789-5793.

17 Strictly speaking, a pair of isoenergetic or almost isoenergetic conformers, separated by a low energy barrier, may exist in a matrix in the true thermodynamic equilibrium with both forms populated in the detectable amounts. However we found that it is not the case for 1,2-butanediol.

18 I. Reva, A. Simão and R. Fausto, Chem. Phys. Lett., 2005, 406, 126-136.

19 A. V. Benderskii and C. A. Wight, J. Phys. Chem., 1996, 100, 14958-14961.

20 (a) C. G. Park and M. Tasumi, J. Phys. Chem., 1991, 95, 2757-2762; (b) H. Takeuchi and M. Tasumi, Chem. Phys., 1983, 77, 21-34.

21 One of the complications in studies of 1,2-butanediol is a low intrinsic intensity of its infrared absorptions. For conformers 1, 6 , 7, 4 and 9 there are, respectively only 3, 3, 4, 2 and 2 bands in the infrared spectrum with the calculated intensities above $60 \mathrm{~km}$ $\mathrm{mol}^{-1}$. In the mixture of conformers, the components' spectra are reduced to less than a half (form 1), or less than $20 \%$ (remaining forms) of their calculated values (see Fig. 5). It is then clear that the resulting absorptions in the experimental spectrum are very weak and required a very long accumulation of the spectral signals.

22 (a) A. D. Becke, Phys. Rev. A, 1988, 38, 3098-3100; (b) A. D. Becke, J. Chem. Phys., 1993, 98, 5648-5652; (c) C. T. Lee, W. T. Yang and R. G. Parr, Phys. Rev. B: Condens. Matter, 1988, 37, 785-789.

23 (a) V. Barone and C. Adamo, J. Chem. Phys., 1996, 105, 11007-11019; (b) M. J. Frisch, J. A. Pople and J. S. Binkley, J. Chem. Phys., 1984, 80, 3265-3269.

24 D. E. Woon and T. H. Dunning, Jr, J. Chem. Phys., 1993, 98 , 1358-1371.

25 M. J. Frisch, G. W. Trucks, H. B. Schlegel, G. E. Scuseria, M. A. Robb, J. R. Cheeseman, V. G. Zakrzewski, J. A. Montgomery, R. E. Stratmann, J. C. Burant, S. Dapprich, J. M. Millam, A. D. Daniels, K. N. Kudin, M. C. Strain, O. Farkas, J. Tomasi, V. Barone, M. Cossi, R. Cammi, B. Mennucci, C. Pomelli, C. Adamo, S. Clifford, J. Ochterski, G. A. Petersson, P. Y. Ayala, Q. Cui, K. Morokuma, D. K. Malick, A. D. Rabuck, K. Raghavachari, J. B. Foresman, J. Cioslowski, J. V. Ortiz, A. G. Baboul, B. B. Stefanov, G. Liu, A. Liashenko, P. Piskorz, I. Komaromi, R. Gomperts, R. L. Martin, D. J. Fox, T. Keith, M. A. Al-Laham, C. Y. Peng, A. Nanayakkara, M. Challacombe, P. M. W. Gill, B. Johnson, W. Chen, M. W. Wong, J. L. Andres, C. Gonzalez, M. Head-Gordon, E. S. Replogle and J. A. Pople, GAUSSIAN 98 (Revision A.9), Gaussian, Inc., Pittsburgh, PA, 1998.

26 C. Y. Peng, P. Y. Ayala, H. B. Schlegel and M. J. Frisch, J. Comput. Chem., 1996, 17, 49-56. 